\title{
Ignition Delay Measurements of a Low-Octane Gasoline Blend, Designed for Gasoline Compression Ignition (GCI) Engines
}

\author{
Mohammed AlAbbad ${ }^{1}$, Jihad Badra ${ }^{2}$, Khalil Djebbi ${ }^{1}$, Aamir Farooq $^{1, *}$ \\ ${ }^{1}$ King Abdullah University of Science and Technology (KAUST), Clean Combustion Research Center, \\ Physical Sciences and Engineering Division, Thuwal, Saudi Arabia \\ ${ }^{2}$ Fuel Technology Division, R\&DC, Saudi Aramco, Dhahran, Saudi Arabia
}

*Corresponding Author: aamir.Farooq@kaust.edu.sa 


\section{Abstract}

A blend of low-octane (light and heavy naphtha) and high-octane (reformate) distillate fuels has been proposed for powering gasoline compression ignition (GCI) engines. The formulated 'GCI blend' has a research octane number (RON) of 77 and a motor octane number (MON) of 73.9. In addition to $\sim 64$ mole $\%$ paraffinic components, the blend contains $\sim 20$ mole $\%$ aromatics and $~ 15$ mole $\%$ naphthenes. Experimental and modelling studies have been conducted in this work to assess autoignition characteristics of the GCI blend. Ignition delay times were measured in a shock tube and a rapid comparison machine over wide ranges of experimental conditions (20 and $40 \mathrm{bar}, 640-1175 \mathrm{~K}, \phi=$ $0.5,1$ and 2). Reactivity of the GCI blend was compared with experimental measurements of two surrogates: a multi-component surrogate (MCS) and a two-component primary reference fuel (PRF 77). Both surrogates capture the reactivity of the fuel quite well at high and intermediate temperatures. The MCS does a better job of emulating the fuel reactivity at low temperatures, where PRF 77 is more reactive than the GCI blend. Ignition delay times of the two surrogates are also simulated using detailed chemical kinetic models, and the simulations agree well with the experimental findings. The results of rate-of-production analyses show important role of cycloalkane chemistry in the overall autoignition behavior of the fuel at low temperatures.

Keywords: Gasoline; compression ignition; naphtha; ignition delay time; shock tube. 


\section{Introduction}

Stringent emissions regulations and demand for higher thermal efficiencies pose serious challenges on the internal combustion (IC) engine technologies powering the transportation sector. Despite these challenges and the increased penetration rate of emerging technologies, such as electric vehicles and hydrogen fuel cells, IC engines are expected to dominate the transportation sector by 2040 (and beyond) according to the latest projections by BP and ExxonMobil $[1,2]$. A possible approach to overcome these environmental challenges is to increase efficiencies and reduce emissions from the existing engine technologies such as gasoline spark ignition (SI) and diesel compression ignition (CI). Such an approach would have potential barriers and would likely increase the cost of ownership of IC engine automobiles. Another strategy would be to explore new engine technologies to address the challenges faced by our communities.

In the last two decades, various advanced compression ignition engines have been investigated as technologies that combine the best of gasoline and diesel engines. Combustion strategies such as homogeneous charge compression ignition (HCCI) [3], reactivity-controlled compression ignition (RCCI) [4-6], and partially-premixed compression ignition (PPCI) [7-10] have sought to combine the benefits of relatively simple design of gasoline engines and their after-treatment systems and the higher efficiencies of diesel engines. The compression ignition combustion mode eliminates traditional engine knock observed in spark-ignition (SI) engines, and removes throttling losses through direct injection (DI). At the same time, greater mixing of fuel and air prior to combustion reduces soot production relative to the conventional mixing-controlled (diesel) combustion.

The fuels powering PPCI combustion mode, also known as gasoline compression ignition (GCI), are generally in the gasoline boiling range. However, the specifications of the enabling fuel are not well defined. Many fuels with varying physical and chemical properties, such as ignition quality, distillation curve and chemical compositions, have been considered in previous works. These include 
conventional gasolines [11-13], diesels [14], gasoline/diesel blends (dieselines) [15, 16], binary or ternary fuel blends (iso-octane, $\mathrm{n}$-heptane and toluene) $[17,18]$ and low-octane gasolines ("naphthas") [19-21]. Many recent studies [19, 22-24] have focused on comparing fuels with different chemical and physical properties in GCI engine operation. Badra et al. [19] investigated the effects of fuels' physical properties on the GCI low-load combustion while using RON 60 fuels. They found that the distillation characteristics of the fuel affect GCI combustion and emissions at early injection timings. Kolodziej et al. [23] analyzed GCI engine performance and emissions using fuels with octane numbers ranging from 60 to 91 . They concluded that RON 80 fuel produced the best overall results for both low- and high-load operation at 15:1 compression ratio. In addition, $\mathrm{HC}$ and $\mathrm{CO}$ emissions were generally reduced at low loads but tended to be higher at mid loads despite the increased reactivity of naphtha compared to gasoline. Cho et al. [22] examined GCI engine combustion and emissions using RON 80 and RON 91 fuels at four different load conditions. They reported that significantly lower fuel consumption was achieved with the higher reactivity (RON 80) fuel due to the lower boost pressure requirements and enhanced combustion. The general conclusion from all such studies is that the fuel reactivity, or the homogenous ignition delay time, is a critical factor in optimizing the performance of GCI engines, and that a RON 80 fuel is more favorable than conventional gasolines for the overall engine performance. It was recently shown that other fuel chemical properties such as the sensitivity [25] and low- and intermediate-temperature heat releases [26] affect GCI combustion and should be considered when designing a GCI fuel.

As mentioned earlier, enabling fuels for the GCI engine concept are not fully understood yet and hence they have not been studied much in homogeneous environments. Recently, our group has measured ignition delay times of a light naphtha stream (RON 64.5) [27] and a straight-run naphtha (RON 60) [28] using the shock tube and rapid compression machine facilities at KAUST. The general conclusion from those two studies is that PRF (primary reference fuel) is a good autoignition surrogate at intermediate and high temperatures. However, a more complex multi-component surrogate is needed 
to match the naphtha reactivity characteristics at low temperatures. It is not obvious if these conclusions would hold for fuels with higher RON and/or fuels containing higher proportions of nonparaffinic components.

In this work, a RON 77 fuel is formulated for GCI engine application and autoignition behavior is studied using shock tube and rapid compression machine. Ignition delay times are measured at various pressures, temperatures and equivalence ratios. Two-component PRF and multi-component surrogates are formulated and their ignition delay times are measured and simulated. Rate-of-production and sensitivity analyses are performed to discuss the reactivity trends of the target fuel and surrogates.

\section{Experimental Details}

\subsection{Fuel Characterization and Surrogate Formulation}

The fuel blend used in this work is a customized mixture of Saudi Aramco hydrotreated light naphtha (50\% vol.), heavy naphtha (25\% vol.), and a high-octane reformate stream (25\% vol.). Various proportions of these three streams were blended and their RON, density and distillation curves were measured. The objective of this blending exercise was to have a fuel with RON near 80 and gasolinelike density and boiling characteristics. The blend discussed here was considered the best compromise with respect to the target properties. We will refer to this blend as 'GCI blend' or 'GCI fuel' in the remainder of the paper. This blend is just one representation of the RON 80 fuels where other fuels with similar octane numbers but different sensitivities, LTHR, lower heating values, etc. might yield different results than the blend presented here. The RON and MON of the GCI blend were measured in a CFR (Cooperative Fuel Research) engine at the Saudi Aramco's Research and Development facility in Dhahran, Saudi Arabia using relevant ASTM methods. Detailed hydrocarbon analysis (DHA) of the GCI blend was also performed at Saudi Aramco. According to the DHA, the GCI blend consists of 145 components with carbon numbers ranging from $\mathrm{C} 3$ to $\mathrm{C} 12$ (no oxygenated species), and an average molecular weight (MW) of 89.97. A few properties of the GCI blend are listed in Table 1, and 
detailed in Table S1 (Supplementary Material).

Two surrogates were formulated in this work to match the properties of the GCI blend. The first is a simple two-component primary reference fuel (PRF) blend to match the RON of the GCI blend. The PRF surrogate contains $77 \%$ vol. iso-octane and $23 \%$ vol. n-heptane, and it is referred as PRF 77 . The second surrogate is a six-component mixture formulated to match $\mathrm{RON}, \mathrm{MON}, \mathrm{H} / \mathrm{C}$, average molecular weight, density and thermal properties of the GCI blend. This surrogate consists of (by mole) $20 \%$ n-pentane, $6 \%$ n-heptane, $23 \%$ 2-methylhexane, 16\% 2,2,4-trimethylpentane, $16 \%$ cyclopentane and $19 \%$ toluene. The six-component surrogate is referred as MCS (multi-component surrogate) in the remainder of the paper. Comparison of some key properties of the GCI blend and its two surrogates is given in Table 1. Basic properties of the surrogate components are listed in Table S2 (Supplementary Material).

\begin{tabular}{|l|c|c|c|}
\hline & GCI & MCS & PRF 77 \\
\hline RON & $77^{\mathrm{a}}$ & $76.7^{\mathrm{c}}$ & 77 \\
\hline MON & $73.9^{\mathrm{a}}$ & $72.2^{\mathrm{c}}$ & 77 \\
\hline Density $\left(\mathrm{kg} / \mathrm{m}^{3}\right)$ & $720.7^{\mathrm{b}}$ & $717.1^{\mathrm{c}}$ & 688.5 \\
\hline Ave. MW & $89.97^{\mathrm{b}}$ & $90.49^{\mathrm{c}}$ & 110.59 \\
\hline C/H & $5.93^{\mathrm{b}}$ & $5.88^{\mathrm{c}}$ & 5.28 \\
\hline Paraffins (\%mol.) & 22.4 & 26 & 25.2 \\
\hline Iso-paraffins (\%mol.) & 41.2 & 39 & 74.8 \\
\hline Naphthenes (\%mol.) & 15.6 & 16 & 0 \\
\hline Aromatics (\%mol.) & 20 & 19 & 0 \\
\hline
\end{tabular}

Table 1. Properties of the GCI blend and its surrogates. ${ }^{a}$ Measured in a CFR engine. ${ }^{b}$ Calculated from the DHA. ${ }^{c}$ Calculated using linear-by-mole relations. Detailed properties of the fuel and surrogates are given in Table SI (Supplementary Material).

In this work, the formulation of MCS was mainly focused on matching the octane numbers and the composition of the non-paraffinic components of the real fuel. Even though molecular structure is a very important indicator of the fuel reactivity, matching the molecular structure of all components of the real fuel can be challenging and can lead to a relatively large surrogate mixture [29] for which detailed or reduced chemical kinetic models may not be available. Computational cost will also be 
high for surrogates containing too many components. Octane numbers (RON and MON) are good overall indicators of the overall reactivity of the fuel, and these can be correlated to ignition delay times at various pressure and temperature conditions $[30,31]$. In addition, octane sensitivity $(\mathrm{S}=\mathrm{RON}$ - MON) correlates quite well with the NTC behavior of the fuel $[32,33]$. We have shown previously that PRF, matching the RON of the real fuel, is a good surrogate for near-zero sensitivity fuels at high and intermediate temperatures $[28,34,35]$. However, the low-temperature reactivity is not strongly correlated to octane numbers but rather depends on the non-paraffinic components present in the real fuel $[27,28,35,36]$. Therefore, in this work, we have prioritized matching the RON, MON and aromatic/naphthenic composition of the GCI blend while formulating the multi-component surrogate (MCS).

\subsection{High-Pressure Shock Tube Facility}

Ignition delay times of the GCI blend were measured using the high-pressure shock tube (HPST) facility at King Abdullah University of Science and Technology (KAUST). The shock tube and the mixing tank were heated to 130 and $150{ }^{\circ} \mathrm{C}$, respectively, to avoid fuel condensation on the internal walls. Sidewall pressure and electronically excited $\mathrm{OH}^{*}$ chemiluminescence at $307 \mathrm{~nm}$ were monitored using Kistler 603B1 PZT and photomultiplier tubes (PMT), respectively. A schematic of the shock tube end-section is shown in Fig. S1 (Supplementary Material). The gradual pressure increase behind reflected shock wave, $\mathrm{dP}_{5} / \mathrm{dt}$, was measured to be approximately $3 \% / \mathrm{ms}$ for non-tailored (helium as driver) shocks and $2 \% / \mathrm{ms}$ for tailored (He/ $\mathrm{N}_{2}$ mixtures as driver) shocks. A molar ratio of 3.76:1 of $\mathrm{N}_{2}: \mathrm{O}_{2}$ was used to prepare fuel/air mixtures. Detailed compositions of the fuel/air mixtures are provided in Table S3 (Supplementary Material). Thermodynamic properties of the GCI blend and the surrogates were calculated using linear-by-mole averaging of the NASA polynomial coefficients of their components. Details of the HPST and the experimental procedure are provided in our previous work [37].

Ignition delay times were measured by monitoring the pressure at the sidewall and/or $\mathrm{OH}^{*}$ at the 
endwall and sidewall. Ignition delay times deduced using these three signals were within 4\%; data reported herein were obtained from the pressure signal. Uncertainty in the reported ignition delay times is estimated to be $+/-15 \%$. A representative shock tube ignition delay time measurement is shown in Fig. S2(a) (Supplementary Material).

\subsection{Rapid Compression Machine Facility}

Ignition delay times at low temperatures were measured in the KAUST rapid compression machine (RCM) facility. The RCM has a twin-opposed piston configuration, a chamber bore of $5.08 \mathrm{~cm}$, a stroke length of $16.9 \mathrm{~cm}$ and volumetric compression ratios of up to 16.8 . Pressure profiles were recorded using a Kistler 6045A pressure transducer. Further details of the RCM facility can be found in our previous work [27].

Ignition delay time for RCM measurements is defined as the time between the end-of-compression (EOC) and the maximum slope of the pressure rise due to ignition, as shown in Fig. $S 2(b)$ (Supplementary Material). Ignition delay times were repeated three times for a single thermodynamic condition, and the reproducibility of the measured data was within $5 \%$ at similar compressed temperature and pressure. The compressed gas temperature $\left(\mathrm{T}_{\mathrm{c}}\right)$ was calculated using isentropic relation from the initial temperature, initial pressure and measured compressed gas pressure $\left(\mathrm{P}_{\mathrm{c}}\right)$. The overall uncertainty in RCM ignition delay times is estimated to be $+/-15 \%$. This uncertainty manly comes from the uncertainty of $\mathrm{T}_{\mathrm{c}}$. The uncertainty of $\mathrm{T}_{\mathrm{c}}$ is related to the measurement of initial pressure, temperature, compressed pressure $\left(\mathrm{P}_{\mathrm{c}}\right)$, partial pressure of the mixture components and the thermodynamic data.

\section{Results and Discussion}

\subsection{Ignition Delay Time Measurements}

Ignition delay times (IDTs) of the GCI blend/air mixtures were measured in the shock tube at two 
pressures (20 and 40 bar), three equivalence ratios $(0.5,1$ and 2$)$, and a range of temperatures (725 $1175 \mathrm{~K})$. Shock tube IDTs spanned $\sim 100 \mu$ s to $5 \mathrm{~ms}$, where driver gas tailoring was used to achieve test times longer than about $1.5 \mathrm{~ms}$. Rapid compression machine (RCM) was used to measure longer ignition delays (up to $\sim 160 \mathrm{~ms}$ ) at 20 bar, three equivalence ratios $(0.5,1$ and 2$)$ and temperatures ranging 640 - $875 \mathrm{~K}$. All measured IDTs are listed in Table S4 (Supplementary Material).

Figure 1(a) shows the effect of pressure and equivalence ratio on the ignition delay times of GCI blend/air mixtures measured in the shock tube. As expected, IDTs show inverse dependence on both pressure and equivalence ratio across the range of temperatures. However, a more pronounced effect of pressure and equivalence ratio on IDTs is observed in the NTC region. The RCM ignition delay time data presented in Fig. 1(b) also show that the dependence on equivalence ratio is strongest in the NTC region and decreases at lower temperatures.

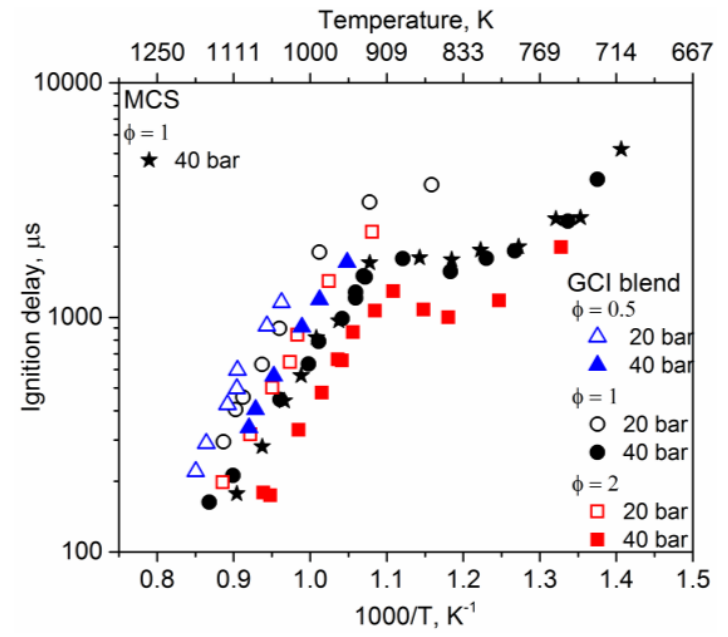

(a)

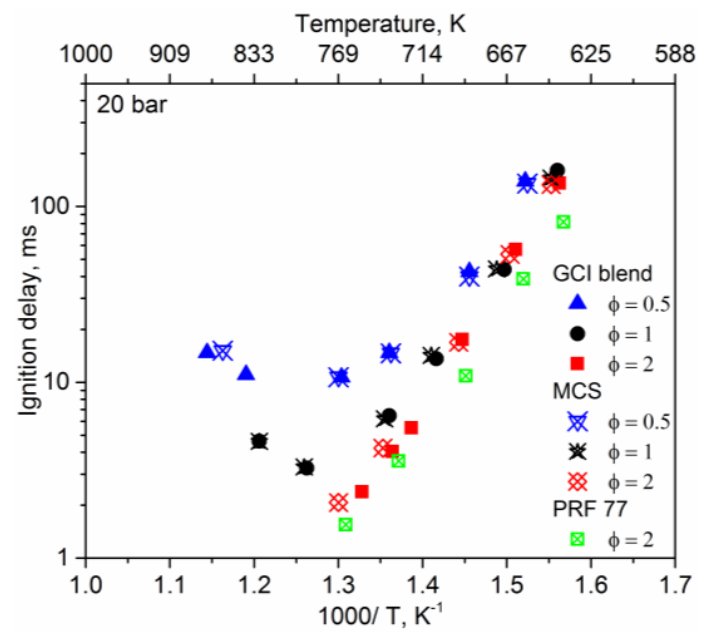

(b)

Fig. 1. Measured ignition delay times of the GCI blend and two surrogates in air (a) Shock tube (b) RCM.

In order to assess the adequacy of the two surrogates in capturing the reactivity of GCI blend, IDTs of PRF 77 and MCS were measured at certain conditions and these are plotted in Fig. 1. Ignition delays of MCS measured in the shock tube at 40 bar and $\phi=1$ (Fig. 1(a)) agree very well with the IDTs of GCI blend at high, intermediate and low temperatures. Comparisons presented in Fig. 1(b) show that 
PRF 77 is more reactive than GCI blend at the low-temperature conditions of the RCM, while the IDTs of GCI blend and MCS are in excellent agreement across the range of temperatures and equivalence ratios.

To illustrate the effect of octane number on fuel reactivity, Fig. 2 compares IDTs of GCI blend (RON 77) with those of straight-run naphtha (RON 60) [28], FACE A/C (RON 83.5 and 84.7) [35] and FACE F/G (RON 94.4 and RON 96.8) [29]. Detailed comparison of these fuels is available in Table S5 (Supplementary Material). Figure 2 shows that the measured IDTs of all fuels show no influence of octane numbers or composition at high temperatures $(\mathrm{T}>900 \mathrm{~K})$. The dependence of IDTs on octane number is strongest in the NTC region. Fuels with high RON (FACE F/G) exhibit very long ignition delay times (near 800 K) compared to fuels with intermediate values of RON (FACE A/C and GCI blend). Shortest ignition delay times are exhibited by Haltermann straight run naphtha (HSRN) which has a RON of 60. Moving from NTC to low temperatures, the effect of octane number decreases. At temperatures near $\sim 650 \mathrm{~K}$, a very weak effect of octane number on ignition delay times is observed. This observation supports our earlier hypothesis that matching the octane number of real fuel, when formulating surrogates, is not enough to capture the low-temperature reactivity.

It may be concluded from the experimental data of the GCI blend and the two surrogates that a multi-component surrogate with non-paraffinic content is needed to match the reactivity at low temperatures where PRF surrogate tends to be too reactive. Similar findings have recently been reported for two low-octane fuels $[27,28]$. It was also shown that these discrepancies in IDT at low temperatures can result in significant differences in the combustion phasing of a CI engine operating at low loads $[28,34]$. 


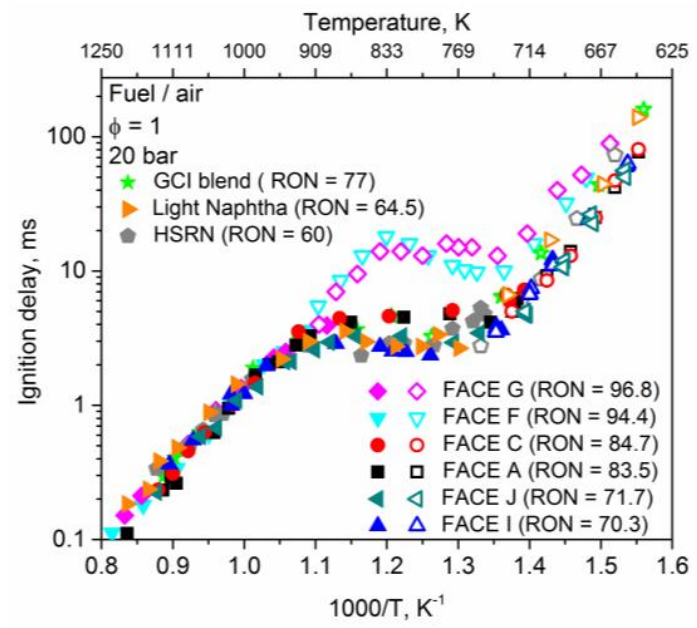

Fig. 2. Dependence of ignition delay times on octane number. Solid symbols are shock tube data, open symbols are RCM data. FACE $F \& G$ data from [29], FACE A \& C from [35], HSRN from [28], GCI blend from this work.

\subsection{Ignition Delay Time Simulations}

Chemical kinetic simulations of the two surrogates, MCS and PRF 77, were carried out and compared with measured IDTs of the GCI blend, MCS and PRF 77. The FACE gasolines mechanism by Sarathy et al. [29] and the gasoline surrogate mechanism by Mehl et al. [38] were used to perform simulations in Chemkin-Pro with a homogeneous batch reactor. The gradual increase in pressure (dP/dt) behind reflected shock waves was considered by employing a corresponding volume profile in shock tube simulations. To account for heat loss in the RCM, non-reactive experiments were performed for each studied condition by replacing $\mathrm{O}_{2}$ with $\mathrm{N}_{2}$ in the reactive mixture. Pressure profiles measured in non-reactive experiments were converted to volume profiles using the adiabatic relationship, and these volume profiles were used for RCM simulations. All non-reactive volume profiles are provided as Supplementary Material.

Figure 3 compares measured and simulated ignition delay times of MCS and PRF 77. Simulations of MCS with Sarathy et al. [29] mechanism successfully reproduce the measured IDTs of MCS for both shock tube and RCM conditions. In our previous work [28], we had noticed that Mehl et al. [38] 
model does a really good job in predicting IDTs of PRF 70 and 80. Therefore, Mehl et al. [38] model was used here to simulate the IDTs of PRF 77. As expected, the predictions agree very well with the IDT measurements of PRF 77 at low temperatures. Figure 3 also shows that the simulated IDTs of the two surrogates are in very good agreement with each other and with the 40 bar MCS experimental data (star symbols) at high and intermediate temperatures. However, at low-temperature RCM conditions, PRF 77 (green solid line) reacts faster than MCS (red solid line). Since experimental IDTs of MCS and GCI blend agreed very well (see Fig. 1), it may be concluded that the Sarathy et al. [29] mechanism and MCS mixture can be used to predict the reactivity of GCI blend over wide ranges of pressure, temperature and equivalence ratio conditions which are relevant to CI engine operation.

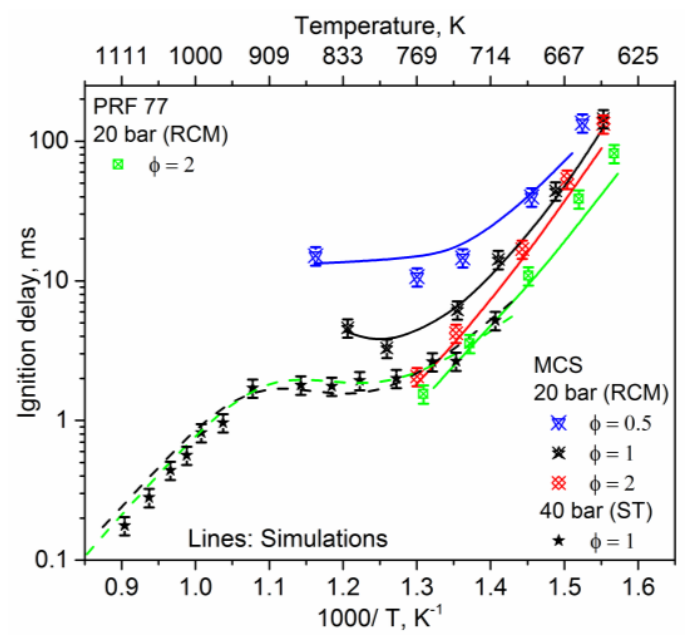

Fig. 3. Comparison between measured and simulated IDTs of MCS and PRF 77. Blue, black and red lines are for the simulated IDTs of MCS at $\phi=0.5,1$ and 2, respectively. Green lines are for PRF 77 simulations.

\subsection{Chemical Kinetic Analysis}

To elucidate the ignition behavior of GCI blend, hydroxyl $(\mathrm{OH})$ and hydroperoxyl $\left(\mathrm{HO}_{2}\right)$ rate-ofproduction (ROP) analyses were performed at low and intermediate temperatures for the multicomponent surrogate (MCS). Figure 4(a) illustrates hydroxyl ROP analysis for MCS at $\phi=2$ and 650 K. At low temperatures, ignition characteristics are very sensitive to $\mathrm{H}$-abstraction from fuel molecules 
by $\mathrm{OH}$ radicals. Cyclopentane $+\mathrm{OH}$ appears to have the highest sensitivity coefficient and inhibits the overall reactivity. Interestingly, although cyclopentane has shorter ignition delay times and lower concentration than toluene in MCS, the overall reactivity (or $\mathrm{OH}$ concentration) is more sensitive to cyclopentane than toluene. This is probably due to the presence of 10 secondary hydrogen atoms in cyclopentane which makes the $\mathrm{H}-a b s t r a c t i o n ~ b y ~ O H$ radical faster [39-42] and thereby strongly affects the radical pool and overall reactivity at low temperatures. Figure $4(b)$ presents $\mathrm{HO}_{2} \mathrm{ROP}$ analysis for MCS at $\phi=2$ and $650 \mathrm{~K}$. The analysis indicates important role of $\mathrm{H}$-abstraction by $\mathrm{HO}_{2}$ at low temperatures. Among all surrogate components, cyclopentane is the largest producer of $\mathrm{HO}_{2}$ radicals. This production of $\mathrm{HO}_{2}$ mainly occurs through the decomposition of cyclopentyl peroxy radical (CPTO2J) to cyclopentene and $\mathrm{HO}_{2}$. Both $\mathrm{OH}$ and $\mathrm{HO}_{2}$ analyses show that reactions involving cyclopentane or its intermediate species are key in promoting or inhibiting the overall reactivity of MCS. This illustrates the massive influence of naphthenic chemistry on the reactivity of multicomponent surrogates at low and intermediate temperatures. We showed in our previous work [28] that replacing toluene by cyclopentane in a TPRF blend leads to a noticeable increase in IDTs at low and intermediate temperatures.

Figure S3 (Supplementary Material) shows ROP analyses of $\mathrm{OH}$ and $\mathrm{HO}_{2}$ for $\mathrm{MCS}$ at an intermediate temperature condition $(825 \mathrm{~K}, 20$ bar and $\phi=2)$. At this temperature, the overall reactivity is controlled by the buildup of $\mathrm{OH}$ radicals and the decomposition of hydrogen peroxide $\left(\mathrm{H}_{2} \mathrm{O}_{2}\right)$ to two $\mathrm{OH}$ radicals. Hydrogen peroxide is primarily produced by $\mathrm{H}$-abstraction reaction from fuel by $\mathrm{HO}_{2}$, thus $\mathrm{HO}_{2}$ formation pathways are important for both low and intermediate temperatures. The analysis also highlights the importance of cyclopentane in promoting or inhibiting the overall reactivity of MCS in the NTC region. 


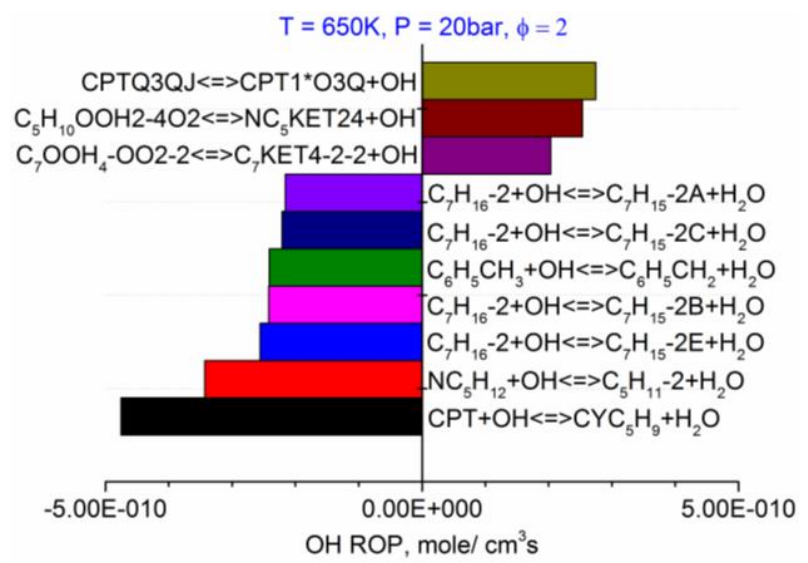

(a)

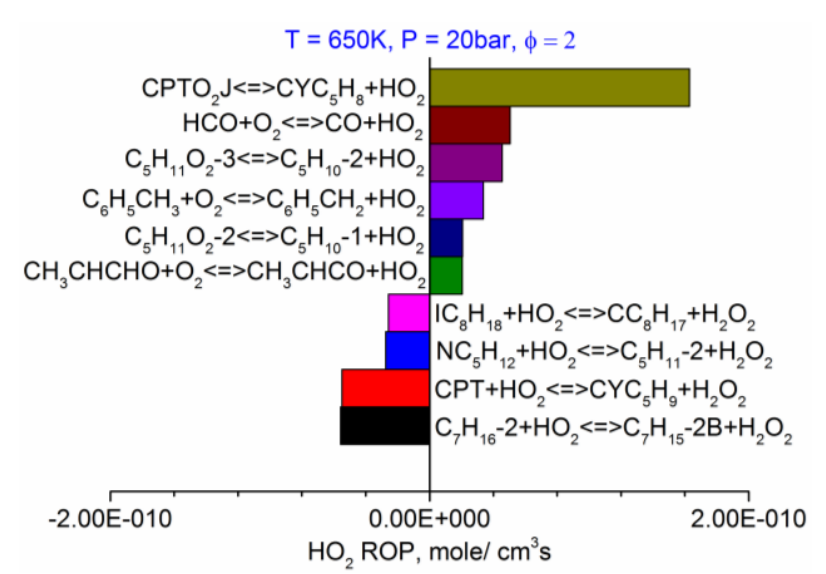

(b)

Fig. 4. Hydroxyl $(\mathrm{OH})$ and hydroperoxyl $\left(\mathrm{HO}_{2}\right)$ rate-of-production analysis for the multi-component surrogate (MCS) using Sarathy et al. [29] model. The analysis is given at 25\% of total ignition delay time.

Figure 5 presents simulated hydroxyl time-history profiles during the oxidation of rich mixtures $(\phi=2)$ of the two surrogates (PRF 77 and MCS) at $650 \mathrm{~K}$ and $825 \mathrm{~K}$. At the high temperature $(825 \mathrm{~K})$, initial growth of $\mathrm{OH}$ radicals is similar for the two surrogates, and only a slight difference in $\mathrm{OH}$ buildup is noticed until the ignition. At the low temperature $(650 \mathrm{~K})$, initially PRF 77 appears to have slower $\mathrm{OH}$ buildup than the MCS; however, after $\sim 5 \mathrm{~ms}$ the $\mathrm{OH}$ radical growth for MCS slows significantly compared to that of PRF 77, and consequently, this results in MCS having much longer IDT than PRF 77. Local maxima in OH radical concentration are observed for all cases shortly before the main ignition event.

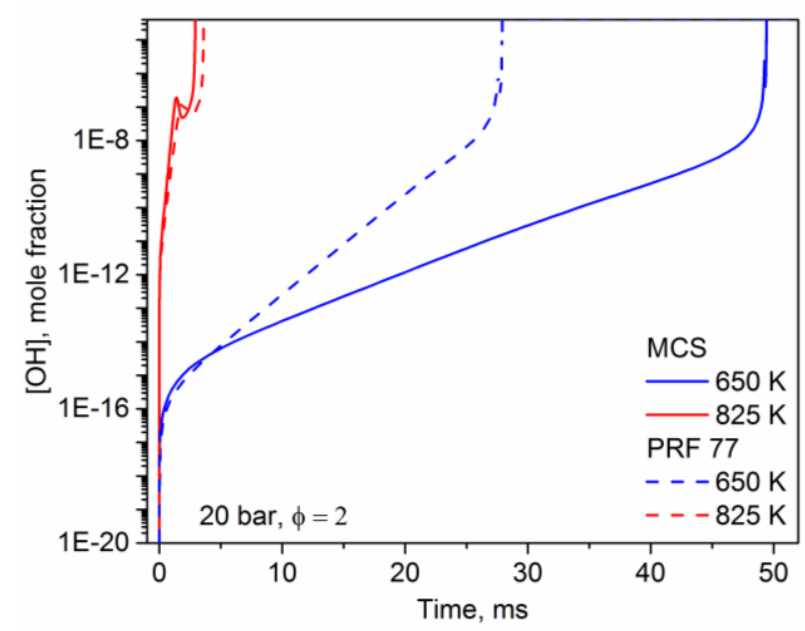


Fig. 5. Hydroxyl time-history during the oxidation of rich mixtures $(\phi=2)$ of MCS and PRF 77. Hydroxyl concentration for Both MCS and PRF 77 simulated using Sarathy et al. [29] mechanism.

\section{Conclusions}

Ignition delay times were measured for a fuel blend formulated for gasoline compression ignition (GCI) engines. Autoignition characteristics of the GCI blend were studied using a shock tube and a rapid compression machine over wide ranges of engine-relevant conditions. Significant influence of pressure and equivalence ratio on IDTs was observed in the NTC region. This effect declined while moving from NTC to high or low temperatures. Two surrogates were formulated to emulate the ignition behavior of GCI blend. Experimental IDTs of PRF 77 and multi-component surrogate (MCS) agreed with GCI blend at high and intermediate temperatures. However, the low-temperature reactivity of the fuel was captured better by MCS due to the presence of non-paraffinic components. These conclusions are in line with previous autoignition studies on low-octane naphtha fuels. Simulated IDTs agreed very well with the measured data, highlighting the fidelity of detailed kinetic mechanisms. Hyroxyl and $\mathrm{HO}_{2}$ rate-of-production analyses indicated that $\mathrm{H}$-abstraction by $\mathrm{OH}$ radicals from cyclopentane and the decomposition of cyclopentyl peroxy are important reactions affecting the overall reactivity of the fuel.

\section{Acknowledgments}

We would like to acknowledge the funding support from Saudi Aramco under the FUELCOM program and by King Abdullah University of Science and Technology (KAUST). 


\section{List of Figures}

Fig. 1. Measured ignition delay times of the GCI blend and two surrogates in air (a) Shock tube (b) RCM.

Fig. 2. Dependence of ignition delay times on octane number. Solid symbols are shock tube data, open symbols are RCM data. FACE F \& G data from [29], FACE A \& C from [35], HSRN from [28], GCI blend from this work.

Fig. 3. Comparison between measured and simulated ignition delay times of MCS and PRF 77. Blue, black and red lines are for the simulated ignition times of the MCS at $\phi=0.5,1$ and 2, respectively. Green lines are for PRF 77 simulations.

Fig. 4. Hydroxyl $(\mathrm{OH})$ and hydroperoxyl $\left(\mathrm{HO}_{2}\right)$ rate-of-production analysis for the multi-component surrogate (MCS) using Sarathy et al. [29] model. The analysis is given at $25 \%$ of total ignition delay time.

Fig. 5. Hydroxyl time-history during the oxidation of rich mixtures $(\phi=2)$ of MCS and PRF 77. Hydroxyl concentration for Both MCS and PRF 77 simulated using Sarathy et al. [29] mechanism.

\section{List of Tables}

Table 1. Properties of the GCI blend and its surrogates. ${ }^{a}$ Measured in a CFR engine. ${ }^{\mathrm{b}}$ Calculated from the DHA. ${ }^{c}$ Calculated using linier-by-mole relations. Detailed properties of the fuel and surrogates are given in Table S1 (Supplementary Material). 


\section{List of Supplementary Material}

Table S1. Properties of the GCI blend and its surrogates. ${ }^{\mathrm{a}}$ Measured in a CFR engine. ${ }^{\mathrm{b}}$ Calculated using linear-by-mole correlation. ${ }^{\mathrm{c}} \mathrm{Cp}$ are calculated using NASA polynomial coefficients. ${ }^{\mathrm{d}}$ Carbon types calculated as per Sarathy et al. [29] methodology.

Table S2. Properties of the species used for multi-component surrogate (MCS) formulation.

Table S3. Molar composition of the mixtures used in ignition delay time measurements

Table S4. Measured ignition delay times and corresponding conditions.

Table S5. Comparison of fuel properties.

Fig. S1. Schematic of the optical configuration for ignition delay time measurements.

Fig. S2. Representative ignition delay time measurement for stoichiometric fuel/air. (a) shock tube (b) rapid compression machine.

Fig. S3. Hydroxyl $(\mathrm{OH})$ and hydroperoxyl $\left(\mathrm{HO}_{2}\right)$ rate-of-production analysis for the multi-component surrogate (MCS) using Sarathy et al. [29] model. The analysis is given at $25 \%$ of total ignition delay.

RCM volume profiles 


\section{References}

[1] BP, in, 2017, pp. 12.

[2] ExxonMobil, in, 2017, pp. 14.

[3] H. Zhao, HCCI and CAI engines for the automotive industry, Elsevier, 2007.

[4] R.M. Hanson, S.L. Kokjohn, D.A. Splitter, R.D. Reitz, SAE International Journal of Engines, 3 (2010) $700-716$.

[5] R.D. Reitz, G. Duraisamy, Progress in Energy and Combustion Science, 46 (2015) 12-71.

[6] A. Ickes, T. Wallner, Y. Zhang, W. De Ojeda, SAE International Journal of Engines, 7 (2014) 860872.

[7] Y. Viollet, J. Chang, G. Kalghatgi, SAE International Journal of Fuels and Lubricants, 7 (2014) 412426.

[8] G. Kalghatgi, P. Risberg, H. Angström, SAE Technical Paper 2006-01-3385, (2006).

[9] J. Badra, A. Elwardany, J. Sim, Y. Viollet, H.G. Im, J. Chang, SAE Technical Paper 2016-01-0762, (2016)

[10] J.A. Badra, J. Sim, A. Elwardany, M. Jaasim, Y. Viollet, J. Chang, A. Amer, H.G. Im, Journal of Energy Resources Technology, 138 (2016) 052202-052202.

[11] G.T. Kalghatgi, L. Hildingsson, A.J. Harrison, B. Johansson, Proceedings of the Combustion Institute, 33 (2011) 3015-3021.

[12] M. Sellnau, M. Foster, K. Hoyer, W. Moore, J. Sinnamon, H. Husted, SAE International Journal of Engines, 7 (2014) 835-851.

[13] M. Sellnau, M. Foster, W. Moore, J. Sinnamon, K. Hoyer, W. Klemm, SAE Int. J. Engines, 9 (2016) 1002-1020.

[14] A.M. Ickes, S.V. Bohac, D.N. Assanis, SAE International Journal of Engines, 10 (2009) 251-263.

[15] D. Han, A.M. Ickes, S.V. Bohac, Z. Huang, D.N. Assanis, Proceedings of the Combustion Institute, 33 (2011) 3039-3046.

[16] F. Zhang, H. Xu, S. Zeraati Rezaei, G. Kalghatgi, S.-J. Shuai, SAE technical Paper 2012-01-1138, (2012)

[17] G. Kalghatgi, L. Hildingsson, A. Harrison, B. Johansson, International Journal of Engine Research, (2011) 452-465.

[18] K.D. Rose, R.F. Cracknell, D.J. Rickeard, J. Ariztegui, W. Cannella, N. Elliott, H. Hamje, M. Muether, T. Schnorbus, A. Kolbeck, M. Lamping, SAE Technical Paper 2010-01-0334, (2010).

[19] J. Badra, Y. Viollet, A. Elwardany, H.G. Im, J. Chang, Applied Energy, 183 (2016) 1197-1208.

[20] J. Chang, G. Kalghatgi, A. Amer, P. Adomeit, H. Rohs, B. Heuser, SAE International Journal of Engines, 6 (2013) 101-119.

[21] Y. Zhang, A. Voice, T. Tzanetakis, M. Traver, D. Cleary, Journal of Engineering for Gas Turbines and Power, 138 (2016) 102805-102805.

[22] K. Cho, E. Latimer, M. Lorey, D.J. Cleary, M. Sellnau, SAE Int. J. Engines, 10 (2017) 1430-1442. 
[23] C.P. Kolodziej, M. Sellnau, K. Cho, D. Cleary, SAE Int. J. Engines, 9 (2016) 979-1001.

[24] J. Storey, S. Lewis, M. Moses-DeBusk, R. Connatser, J. Lee, T. Tzanetakis, K. Cho, M. Lorey, M. Sellnau, SAE Int. J. Engines, 10 (2017) 1454-1464.

[25] K. Cho, Y. Zhang, D. Cleary, in, SAE Technical Paper, 2018.

[26] J.E. Dec, Proceedings of the combustion institute, 32 (2009) 2727-2742.

[27] T. Javed, E.F. Nasir, A. Ahmed, J. Badra, K. Djebbi, M. Beshir, W. Ji, S.M. Sarathy, A. Farooq, Proceedings of the Combustion Institute, 36 (2017) 315-322.

[28] M. Alabbad, G. Issayev, J. Badra, A.K. Voice, B.R. Giri, K. Djebbi, A. Ahmed, S.M. Sarathy, A. Farooq, Combustion and Flame, 189 (2018) 337-346.

[29] S.M. Sarathy, G. Kukkadapu, M. Mehl, T. Javed, A. Ahmed, N. Naser, A. Tekawade, G. Kosiba, M. AlAbbad, E. Singh, S. Park, M.A. Rashidi, S.H. Chung, W.L. Roberts, M.A. Oehlschlaeger, C.-J. Sung, A. Farooq, Combustion and Flame, 169 (2016) 171-193.

[30] N. Naser, S.Y. Yang, G. Kalghatgi, S.H. Chung, Fuel, 187 (2017) 117-127.

[31] J.A. Badra, N. Bokhumseen, N. Mulla, S.M. Sarathy, A. Farooq, G. Kalghatgi, P. Gaillard, Fuel, 160 (2015) 458-469.

[32] W.R. Leppard, in, SAE Technical Paper, 1990.

[33] M. Mehl, T. Faravelli, F. Giavazzi, E. Ranzi, P. Scorletti, A. Tardani, D. Terna, Energy \& fuels, 20 (2006) 2391-2398.

[34] T. Javed, A. Ahmed, L. Lovisotto, G. Issayev, J. Badra, S.M. Sarathy, A. Farooq, Combustion and Flame, 185 (2017) 152-159.

[35] S.M. Sarathy, G. Kukkadapu, M. Mehl, W. Wang, T. Javed, S. Park, M.A. Oehlschlaeger, A. Farooq, W.J. Pitz, C.-J. Sung, Proceedings of the Combustion Institute, 35 (2015) 249-257.

[36] M. Tao, T. Wu, H. Ge, D. DelVescovo, P. Zhao, Combustion and Flame, 185 (2017) 234-244.

[37] M. AlAbbad, T. Javed, F. Khaled, J. Badra, A. Farooq, Combust. Flame, 178 (2017) 205-216.

[38] M. Mehl, W.J. Pitz, C.K. Westbrook, H.J. Curran, Proc. Combust. Inst., 33 (2011) 193-200.

[39] D. Liu, F. Khaled, B.R. Giri, E. Assaf, C. Fittschen, A. Farooq, The Journal of Physical Chemistry A, 121 (2017) 927-937.

[40] J. Badra, F. Khaled, B.R. Giri, A. Farooq, Physical Chemistry Chemical Physics, 17 (2015) 24212431.

[41] J. Badra, A. Elwardany, A. Farooq, Proceedings of the Combustion Institute, 35 (2015) 189-196.

[42] R. Sivaramakrishnan, J.V. Michael, Combustion and Flame, 156 (2009) 1126-1134. 